\title{
MRI AND FNAC ARE USEFUL TOOLS IN PRE-OPERATIVE DIAGNOSIS OF ANCIENT SCHWANNOMA: A CASE REPORT
}

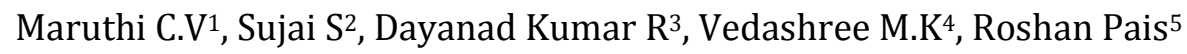

\section{HOW TO CITE THIS ARTICLE:}

Maruthi CV, Sujai S, Dayanad Kumar R, Vedashree MK, Roshan Pais. "MRI and FNAC are useful tools in preoperative diagnosis of ancient schwannoma: a case report". Journal of Evolution of Medical and Dental Sciences 2013; Vol2, Issue 34, August 26; Page: 6377-6381.

ABSTRACT: INTRODUCTION: Ancient schwannomas are rare encapsulated tumours that derive from the nerve sheath and should be removed due to their infrequent but existent possibility of malignancy. CASE PRESENTATION: We report a case of a mass located in the L4 lumbar spine in a 50 year old woman who presented with low back ache since 6 months. Ultrasound, CT and MRI were used to examine the characteristics of the lesion. Fine needle aspiration showed cytological characteristics of a benign schwannoma and final histological diagnosis was an Ancient schwannoma. A posterior approach, through a left paraspinal incision was used to approach the site of the mass. The lesion originated from a branch of the L4 nerve root of the L4-L5 lumbar spinal space and a complete excision was achieved, preserving the nerve. CONCLUSION: Paraspinal tumours can be benign to most aggressive lesions. It is therefore a necessity for the surgeon to understand the pathology preoperatively by a MRI and FNAC, to avoid overtreatment and major complications.

KEY WORDS: Ancient schwannoma, MRI, FNAC, Paraspinal mass.

INTRODUCTION: Paraspinal tumors often pose a diagnostic dilemma for the surgeon, frequently due to their silent clinical course and great similarities in radiological characteristics. A variety of heterogeneous lesions should be investigated when a paraspinal lesion is discovered. MRI has improved our ability to differentiate these masses, although significant limitations persist. Preoperative FNAC may be very useful, however only the final histological examination can definitively establish the real nature of the lesion.

Ancient schwannoma's are rare, well encapsulated tumours, of long duration, mostly benign in nature. They are usually solitary, may grow to a large size before detection. Degenerative changes are typified by relative loss of Antoni type A tissue, perivascular hyalinisation, calcification, cystic necrosis, areas of haemorrhage, presence of degenerative nuclei and quite often misinterpreted as a sarcomatous pleomorphism.

CASE DETAILS: A 50-year-old woman of Bangalore rural origin presented with low back ache since six months. Examination of spine revealed diffuse tenderness from Dl2 to S1. No evidence of neurovascular deficit was found in lower limbs. Systemic examination did not reveal any findings and Laboratory investigations were unremarkable.

MRI: MRI of Lumbosacral Spine revealed an incidental finding of a paraspinal mass demonstrating homogeneous low signal intensity on the T1- weighted and a high signal on the T2-weighted. The lesion was in association with the L4-L5 inter spinal space and seemed to arise from the spinal root (Figure: 1). 
FNAC: Ultrasonography guided FNAC revealed Left sided paraspinal lesion measuring $2.9 \mathrm{~cm} \times 2.7 \mathrm{~cm}$ $\mathrm{x} 1.6 \mathrm{~cm}, 1.7 \mathrm{~cm}$ beneath the skin with a maximum depth of $4.7 \mathrm{~cm}$, solid, well defined mass with mixed echogenicity in the left paraspinal region, with no further pathology. Microscopic examination revealed spindle cells with fibrillary cytoplasm arranged in interlacing fascicles \& exhibiting nuclear palisading with mild to moderate nuclear pleomorphism. No mitotic activity was seen and was suggestive of an Ancient Schwannoma (Figure: 2).

TREATMENT: An excisional biopsy was done under general anaesthesia through a left sided posterior paraspinal approach. The mass seemed to originate from the posterior branch of L5 nerve root of the L4-L5 lumbar spinal space; it was well circumscribed and showed no evidence of infiltration into the surrounding structures and was excised completely, preserving the nerve of origin (Figure: 3). Post operative period was un-eventful and patient did not develop any neurological deficit. The patient is now able to walk without pain \& carry out her daily activities with the support of a lumbosacral belt, analgesics, bisphosphonates, calcium supplements.

HISTOLOGY: Section studied showed a neoplasm composed of a mixture of Antoni A \& Antoni B areas. Antoni A areas are hypercellular areas having spindle shaped cells, exhibiting twisted nuclei \& intranuclear vacuoles \& palisading of the nuclei forming verocay bodies. Tumor cells show indistinct fibrillary cytoplasm. Antoni B areas are the hypocellular areas. Blood vessels show perivascular hyalination. Bizarre nuclei were noted. No mitotic activity was seen. Features are suggestive of schwannoma with degenerative changes: Ancient Schwannoma (Figure: 4).

DISCUSSION: The first case of schwannoma was described in 1954. Schwannomas make up 0.5\% $1.2 \%$ of retroperitoneal tumors. Retroperitoneal localization affects males and females of mid 50's with a ratio of 2:3. Asymptomatic types are the most common forms, thus making an early diagnosis difficult, although nonspecific abdominal or back pain may occur.

Schwannomas with pronounced degenerative changes are known as ancient schwannomas, these are quite rare and usually are deep seated large mass of long duration $[1,2]$. They represent $0.8 \%$ of all soft-tissue tumours [3]. The term "ancient neurilemmoma" was first suggested by Ackerman and Taylor [4]. The authors reported 10 patients with tumours showing features similar to those of typical neurilemmomas, but differing in that significant tumour portions contained only a few cells within hyalinized matrices. They found that these features occurred in schwannomas of long duration, and hence coined the term "ancient schwannoma".

Such tumours are characterised by diffuse hypocellular areas, relative loss of Antoni type A tissue, focal accumulations of hyaline material, calcification, cystic necrosis, haemorrhage and fatty degeneration $[5,8]$.

In addition, as the tumours are usually infiltrated by large numbers of siderophages and histiocytes, and display cellular degenerative changes, including nuclear atypia and pleomorphism, along with a tendency to nuclear palisading [1], malignancy may be erroneously diagnosed [4].

The use of fine needle aspiration (FNA) in above lesions is supported by many studies and along with CT and MRI, as it may increase the accuracy of preoperative diagnosis [6]. The accuracy, sensitivity and specificity of FNA in mesenchymal tumors have been reported at approximately $90 \%$, showing that FNA may be used with precision for preoperative evaluation [7] 
On MRI, the ancient schwannoma shows well-circumscribed, homogeneous signal intensity and a different enhancement pattern. According to the findings of Isobe and colleagues [8], the circumferences of the degenerated area and fibrous tumour capsule enhanced on MRI are important for discriminating an ancient schwannoma from other tumours [9, 10]. Our case showed hypointense fibrous capsules and enhancements. The split fat sign is more common in benign nerve sheath tumours and lesions of large nerves, whereas malignant nerve sheath tumours less frequently demonstrate complete fat rims, reflecting the more infiltrative growth patterns of such tumours [11].

Two MRI features are important for differentiating ancient schwannoma from other malignant tumours: the mass should have a fibrous capsule and the split fat sign should be evident.

CONCLUSION: Paraspinal tumours can be benign to aggressive lesions. It is therefore necessity for the surgeon to understand the pathology preoperatively by MRI and FNAC, to avoid overtreatment and major complications.

\section{REFERENCES:}

1. Enzinger FM, Weiss SW. Benign tumors of peripheral nerves. Soft tissue tumors, 3rd edn. St Louis: Mosby; 1995:821-88.

2. Takeuchi M, Matsuzaki K, Nishitani H, Uehara H. Ancient schwannoma of the female pelvis. Abdom Imaging2008; 33:247-52.

3. Dahl I. Ancient neurilemmoma (schwannoma). Acta Pathol Microbiol Scand Sect A 1977; 85:812-18.

4. Ackerman LV, Taylor FH. Neurogenous tumors within the thorax: a clinicopathological evaluation of forty-eight cases. Cancer: 1951; 4:669-91.

5. Eversole LR, Howell RM. Ancient neurilemmoma of the oral cavity. Oral Surg Oral Med Oral Pathol 1971; 32:440-3.

6. Li Q, Gao C, Juzi JT, Hao X: Analysis of 82 cases of retroperitoneal schwannoma. ANZ J Surg 2007, 77(4):237-240.

7. Maitra A, Ashfaq R, Saboorian MH, Lindberg G, Gokaslan ST: The role of fine-needle aspiration biopsy in the primary diagnosis of mesenchymal lesions: a community hospitalbased experience. Cancer 2000, 90(3):178-185

8. Isobe K, Shimizu T, Akahane T, Kato H. Imaging of ancient schwannoma. AJR Am J Roentgenol 2004; 183:331-6

9. Inokuchi $\mathrm{T}$, Takiuchi H, Moriwaki $\mathrm{Y}, \mathrm{Ka} \mathrm{T}$, Takahashi $\mathrm{S}$, Tsutsumi $\mathrm{Z}$, et al. Retroperitoneal ancient schwannoma Presenting as an adrenal incidentaloma: CT and MR findings. Magn Reson Imaging 2006; 24:1389-93.

10. Loke TK, Yuen NW, Lo KK, Lo J, Chan JC. Retroperitoneal ancient schwannoma: review of clinic-radiologic features. Australas Radiol: 1998; 42:136-8.

11. Kransdorf MJ, Murphey MD, editors. Neurogenic tumors. Imaging of soft tissue tumors, 2nd edn. Philadelphia, PA: Lippincott Williams \& Wilkins; 2006: 328-80. 


\section{CASE REPORT}

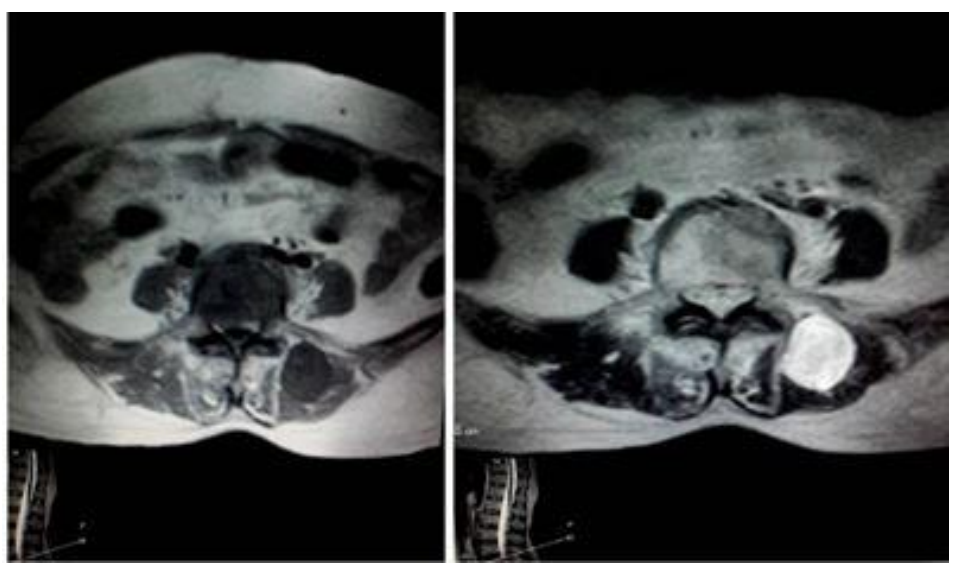

Fig. 1
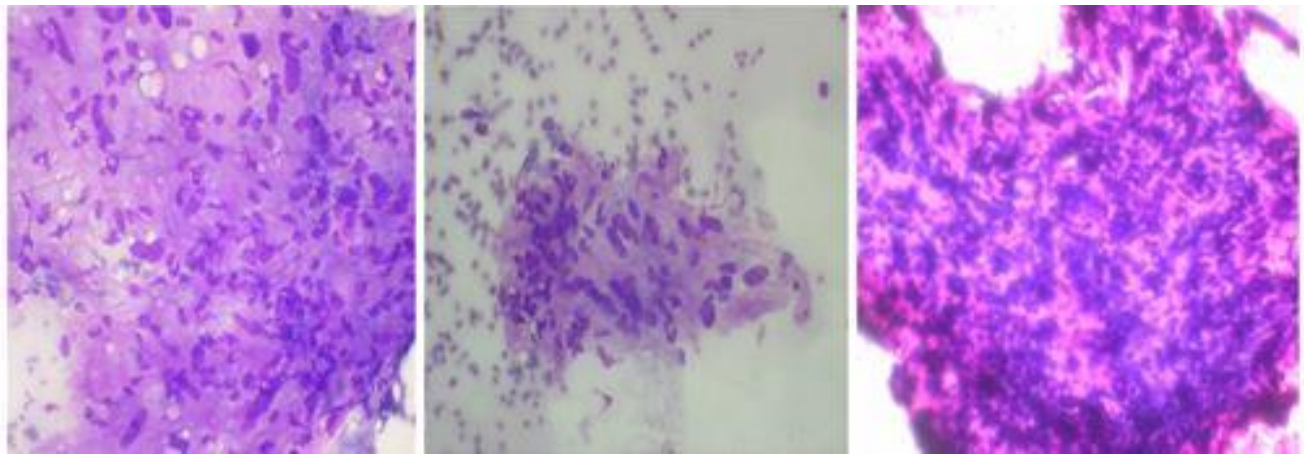

Fig. 2

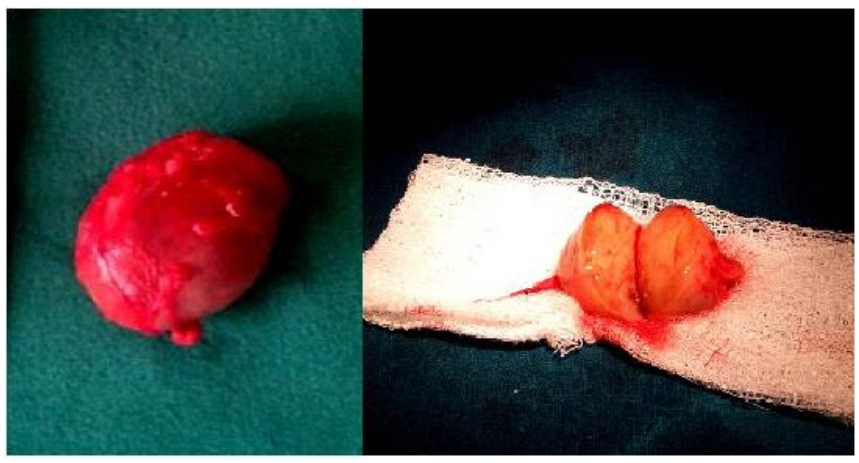

Fig. 3
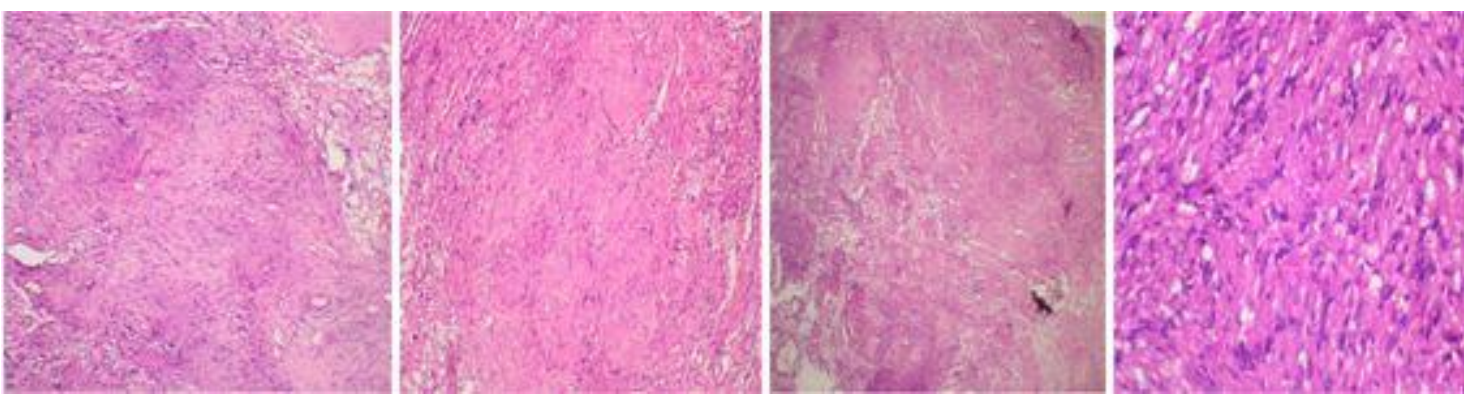

Fig. 4 


\section{AUTHORS:}

1. Maruthi C.V.

2. Sujai $\mathrm{S}$.

3. Dayanad Kumar R

4. Vedashree M.K

5. Roshan Pais

\section{PARTICULARS OF CONTRIBUTORS:}

1. Assistant Professor, Department of Orthopaedics, M.V.J. Medical College and Research Hospital, Hoskote, Bangalore.

2. Assistant Professor, Department of Orthopaedics, M.V.J. Medical College and Research Hospital, Hoskote, Bangalore.

3. Assistant Professor, Department of Radiodiagnosis, M.V.J. Medical College and Research Hospital, Hoskote, Bangalore.
4. Assistant Professor, Department of Pathology, M.V.J. Medical College and Research Hospital, Hoskote, Bangalore.

5. Assistant Professor, Department of Orthopaedics, M.V.J. Medical College and Research Hospital, Hoskote, Bangalore.

\section{NAME ADDRESS EMAIL ID OF THE} CORRESPONDING AUTHOR:

Dr. Maruthi C.V., $6^{\text {th }}$ Cross, Opp. APMC Yard, Sir. M. V. Layout, M.G. Road, Chickballapur - 562101.

Email-cvmaruthi@sify.com

Date of Submission: 31/07/2013.

Date of Peer Review: 16/08/2013.

Date of Acceptance: 19/08/2013.

Date of Publishing: 20/08/2013 